\title{
Стержневые элементы тектоники Восточно-Арктической континентальной окраины Евразии
}

\author{
Шипилов Э.В. ${ }^{1}$, Лобковский Л.И. ${ }^{2}$ \\ ${ }^{1}$ Полярный геофизический институт, Мурманск, shipilov@pgi.ru \\ ${ }^{2}$ Институт океанологии РАН, Москва, llobkovsky@ocean.ru
}

\begin{abstract}
Аннотация. Исследование структуры, тектоники и геодинамической эволюции литосферы Арктического региона и его континентальных окраин с геохронологическим ранжированием стадийно формирующихся осадочных бассейнов, в том числе ключевых в нефтегазоносном отношении, представляет одну из фундаментальных проблем современной геологии и геофизики. В этой связи нами были проинтерпретированы несколько групп региональных сейсмических профилей перекрывающих различные сегменты ВосточноАрктического шельфа России. Интерпретация профилей применительно к разрабатываемой авторами модели геодинамической эволюции Арктики позволила получить новую и дополнительную информацию о строении и развитии разных по устройству и тектоническим преобразованиям областей литосферы Арктической континентальной окраины Евразии.
\end{abstract}

Ключевые слова: Восточно-Арктический шельф, континентальная окраина, тектоника, эволюция, геофизика, сейсмические исследования, интерпретация, геодинамическая модель.

\section{Core elements of tectonics of the Eastern Arctic continental margin of Eurasia}

\author{
Shipilov E.V. ${ }^{1}$, Lobkovsky L.I. ${ }^{2}$ \\ ${ }^{1}$ Polar geophysical institute, Murmansk, shipilov@pgi.ru \\ ${ }^{2}$ Institute of Oceanology, RAS, Moscow, llobkovsky@ocean.ru
}

\begin{abstract}
The study of the structure, tectonics and geodynamic evolution of the lithosphere in the Arctic region and its continental margins with geochronological ranking of stage-forming sedimentary basins, including the key ones in terms of the oil and gas potential, is one of the fundamental issues of modern geology and geophysics. In this regard, we have interpreted several groups of regional seismic profiles covering different segments of the Eastern Arctic shelf of Russia. The interpretation of the profiles in relation to the model of geodynamic evolution of the Arctic developed by the authors has allowed to obtain new and additional information about the structure and development of different structure and tectonic transformations of the lithosphere regions of the Arctic continental margin of Eurasia.

Key words: East Arctic shelf, continental margin, tectonics, evolution, geophysics, seismic studies, interpretation, geodynamic model.
\end{abstract}

\section{Введение}

Интерпретация групп сейсмических профилей применительно к разрабатываемой авторами модели геодинамической эволюции Арктики (Лаверов и др., 2012; Лобковский и др., 2013; Шипилов, Лобковский, 2012; Shipilov, 2008) позволила получить новую и дополнительную информацию о строении и развитии различающихся по устройству и тектоническим преобразованиям областей литосферы Восточно-Арктической континентальной окраины Евразии.

Первая группа профилей охватывает в основном северный сегмент шельфа моря Лаптевых, другая - шельф Восточно-Сибирского моря, третья группа сконцентрирована в южной и северной частях шельфа Чукотского моря (рис. 1).

Лаптевоморская континентальная окраина характеризуется тем, что в ее пределах основная структурно-тектоническая ситуация обусловлена развитием системы разветвленных позднемеловых-кайнозойских рифтовых бассейнов (Богданов и др., 1998; Верниковский и др., 2010; Шипилов, 2001; 2004; Shipilov, 1989). Они имеют субсогласное с хр. Гаккеля простирание и обрубаются континентальным склоном и адаптированным к нему Хатангско-Ломоносовским линеаментом (Богданов и др., 1998; Головачев, Шипилов, 1986; Шипилов, 2001; 2004; Шипилов, Шкарубо, 1998). К зоне линеамента тяготеют эпицентры некоторых землетрясений и множественные прорыва 


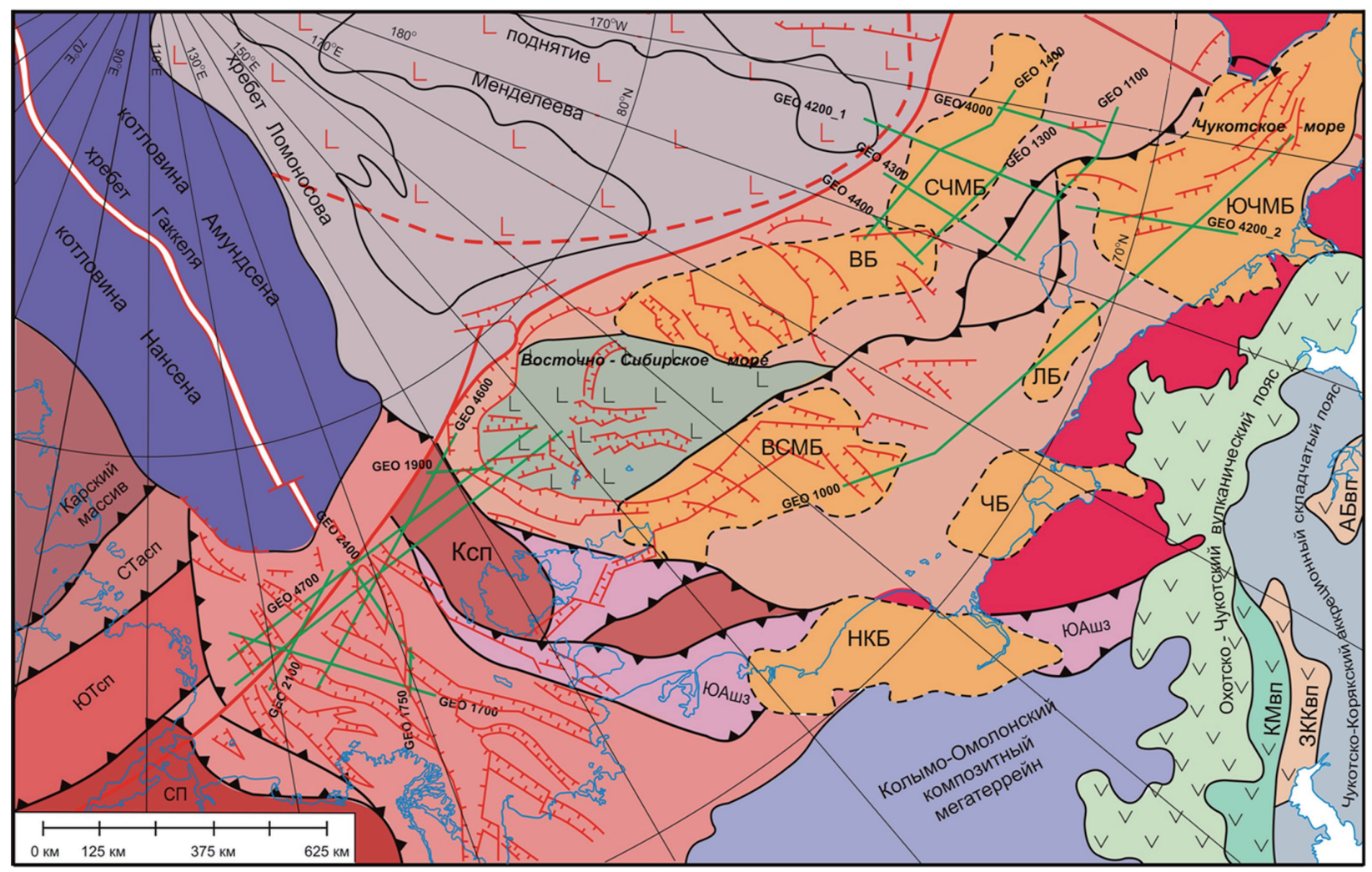

Рис. 1. Структурно-тектоническая схема Восточной Арктики и расположение некоторых сейсмических профилей (зеленые линии).

Ксп - Котельнический складчатый пояс; ЮАшз - Южно-Анюйская шовная зона; основные осадочные бассейны: НКБ - Нижне-Колымский, ЧБ - Чаунский, ЛБ - Лонга, ВСМБ - Восточно-Сибирского моря (Благовещенский), ВБ - Вилькицкого, СЧМБ - Северо-Чукотский, ЮЧМБ - Южно-Чукотский.

Fig. 1. Structural-tectonic scheme of the Eastern Arctic and the location of some seismic profiles (green lines). Ксп - Kotelny fold belt; ЮАшз - South-Anyui suture zone; main sedimentary basins: НКБ - Lower-Kolyma, ЧБ Chaun, ЛБ - Longa, ВСМБ - East Siberian Sea, ВБ - Vilkitsky, СЧМБ - North-Chukotka, ЮЧМБ - South-Chukotka.

метана (засвеченные зоны на сейсмических разрезах) в виде т.н. газовых труб и потоков, что, несомненно, свидетельствует о его разломообразующей природе. Отрезок этого нарушения, лежащий к западу от района сочленения с хребтом Гаккеля, на этапе раскрытия Евразийского бассейна был малоактивен. В то же время восточная часть разлома, как представляется, играла заметную сдвиговую роль на раннем этапе формирования Евразийского бассейна. В результате эта разломная зона определила прямолинейный характер границы северо-восточной части Лаптевоморской окраины с впадиной Амундсена. Различие в кинематике западной и восточной частей

Хатангско-Ломоносовской зоны разломов, по всей видимости, предопределило асимметрию в строении Евразийского бассейна (Богданов и др., 1998). Сейсмические разрезы показывают, что продолжение сегмента рифтовой долины хр. Гаккеля на Лаптевоморском шельфе оказывается несколько смещенным к востоку относительно его Евразийского окончания. В тектоническом плане этот позднекайнозойский грабен унаследовал положение тектонического шва, разделяющего шельфовый блок Сибирской платформы и продолжающуюся сюда Южно-Анюйскую зону деформаций. Последняя, в свою очередь, получила развитие в области взаимодействия шельфового блока Сибирской платформы и Котельнического массива.

Континентальная окраина Восточно-Сибирского и Чукотского морей. В отличие от Лаптевоморского региона здесь получили развитие преимущественно субширотно ориентированные бассейны, меняющие свое простирание на 3-С-3 при обрамлении ими поднятия Де-Лонга, что указывает на обособленный характер эволюции этой части окраины в допозднемеловое время. Структурно- 

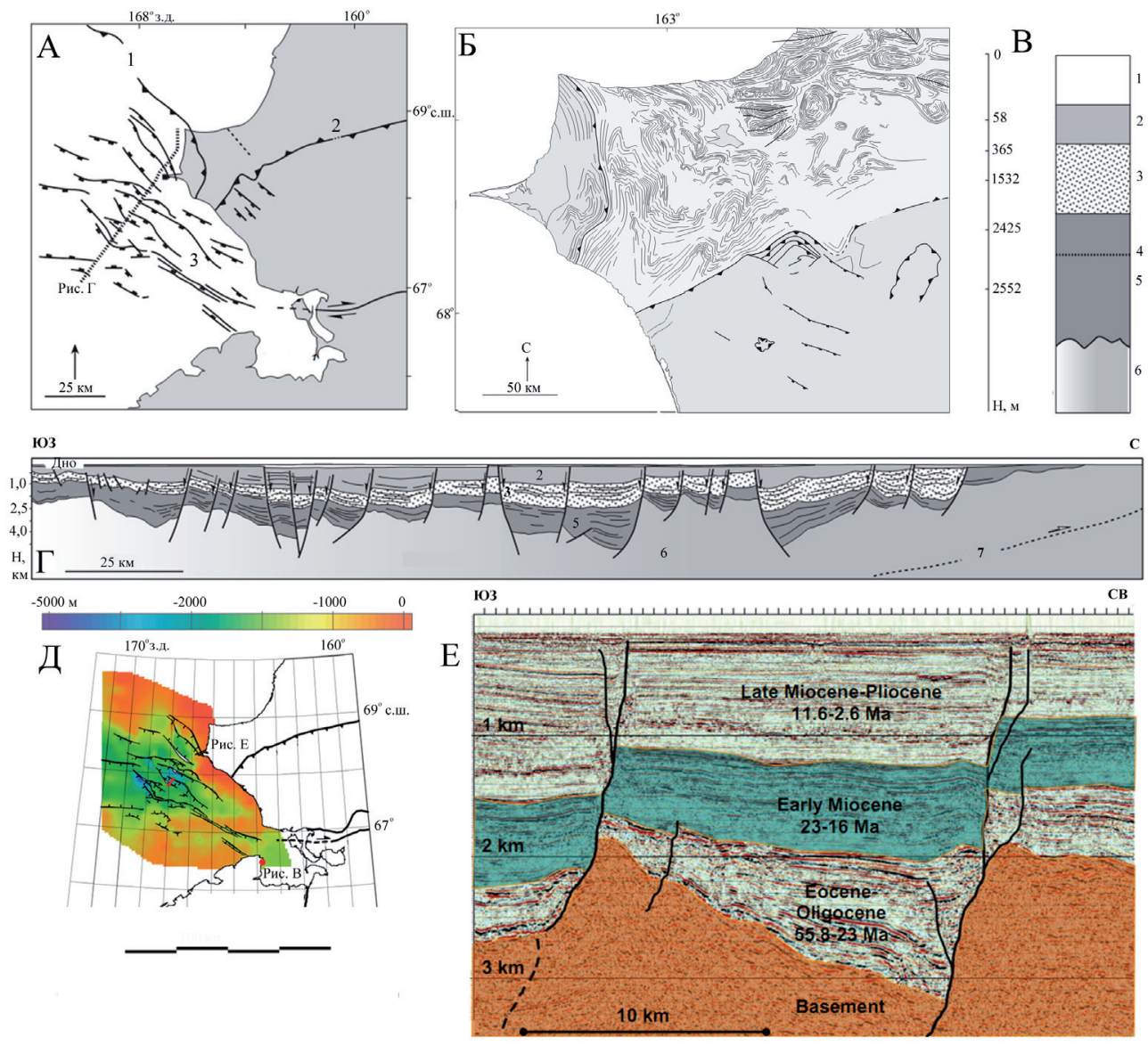

Рис. 2. Строение юго-востока Чукотского шельфа и тектоническая природа бассейна Хоуп.

A. Схема сбросов и сбросо-сдвигов впадины Хоуп и расположение линии сейсмического разреза (de Vera, 2005). 1 - Врангелевско-Геральдское надвиговое поднятие, 2 - хр. Брукса, 3 - впадина Хоуп.

Б. Характер дислокаций с-з части Аляски и мыса Лисбурн по результатам дешифрирования космоснимка «Landsat» (NASA, 2005) (de Vera, 2005). В. Разрез отложений, вскрытых скважиной Эспенберг 1 (Espenberg) (Elswick, Toro, 2003) на востоке бассейна Хоуп. Положение скважины на рис. Д. Слева шкала глубин (м). Цифры справа - литолого-стратиграфические образования: 1 - гляциальные, плейстоцен; 2 - мелководноморские, поздний миоцен-плиоцен; 3 - морские и неморские, миоцен; 3 - вулканогенные, с возрастом 40-42 млн. лет (K-Ar); 5 - неморские, эоцен-олигоцен; 6 - фундамент, домиссиссипий. Г. Сейсмогеологический разрез (расположение линии на рис. А), характеризующий грабенообразную природу бассейна Хоуп (Tolson, 1987; Elswick, Toro, 2003). Комплексы отложений соответствуют рис. В. 7 - Геральдский надвиг. Д. Схема рельефа поверхности фундамента и сбросов (McDannell et al., 2014), формирующих грабенообразную структуру бассейна Хоуп. Е. Фрагмент интерпретированного сейсмического разреза в центральной части бассейна Хоуп (Elswick, Toro, 2003). Положение линии разреза на рис. Д.

Fig. 2. The structure of the South-East of the Chukchi shelf and the tectonic nature of the Hope basin. A. Scheme of faults in the Hope depression and the location of the seismic section line (de Vera, 2005). 1-WrangelHeraldic thrust ridge, 2 - ridge Brooks, 3 - Hope basin. Б. The nature of dislocations of the N-W Alaska and Cape Lisburn on the results of decoding the space image «Landsat» (NASA, 2005) (de Vera, 2005). B. The section of the deposits uncovered by the borehole, Espenberg 1 (Elswick, Toro, 2003) in the East basin Hope. Well position in Fig. D. Left depth scale (m). Figures on the right-lithological-stratigraphic formations: 1 - glacial, Pleistocene; 2 - shallowsea, late Miocene-Pliocene; 3 - marine and non-marine, Miocene; 3-volcanogenic, with the age of 40-42 million years (K - Ar); 5-non-marine, Eocene-Oligocene; 6- basement, Premissippi. $\Gamma$. Seismogeological section (location of the line in Fig. (A), characterizing the graben-like nature of the Hope basin (Tolson, 1987; Elswick, Toro, 2003). The sediment complexes correspond to Fig. B. 7- Herald thrust. Д. Scheme of the surface topography of the basement and normal fault (McDannell et al., 2014), forming the graben-like structure of the Hope basin. E. Fragment of interpreted seismic section in the central part of the Hope basin (Elswick, Toro, 2003). The position of the line in Fig. Д. 
тектонический каркас окраины (как плиты) образован тремя основными полосами субширотных тектонических элементов - Южно-Чукотским, Лонга и др. и Новосибирско-Северо-Чукотским рифтогенными осадочными мегабассейнами и разделяющим их Врангелевско-Геральдским поднятием (дугой), связанным с серией осложняющих складчато-надвиговых дислокаций преимущественно северной вергентности и, отчасти, южной. Вопреки сложившимся представлениям о повсеместном распространении чехла только лишь мелового-кайнозойского возраста, в северных звеньях (СевероЧукотский бассейн и его продолжения на запад) осадочный чехол может достигать 15-20 км в связи с присутствием в низах разреза, как показывают результаты бурения и сейсмические данные, верхнепалеозойских комплексов (Верба, 2016; Шипилов, 2016). Тогда как на юге (Южно-Чукотский бассейн) его значения составляют 3-5 км (Shipilov, 1989), и наиболее древними образованиями здесь могут быть апт-альбские или верхнемеловые отложения, хотя во впадине Хоуп скважиной Эспенберг вскрыты залегающие на фундаменте лишь кайнозойские образования (Elswick, Toro, 2003) (рис. 2). Таким образом, возраст складчатого основания осадочного чехла южной системы бассейнов является позднемезозойским (доаптским), а северной - преимущественно каледонским (элсмириды).

Стержневой структурой Восточно-Арктического шельфа является цепь бассейнов, состоящая из глубоких прогибов Вилькицкого (рис. 1) и его продолжений к западу - Новосибирского и к востоку - Северо-Чукотского. В их депоцентрах мощность осадочного чехла составляет от 10-12 до 18-20 км. Учитывая разночтения в названиях бассейнов у разных авторов эта цепь глубочайших прогибов выделяется как Новосибирско - Северо-Чукотский мегапрогиб.

На фоне отмеченных рифтогенных прогибов особняком выделяется поднятие (купол) ДеЛонга, в пределах которого и по его периферии развиты узкие грабенообразные структуры как альбаптского, так и кайнозойского возраста с ясно выраженной сбросовой тектоникой и с проявлениями соответствующего базальтоидного магматизма. Активизация тектонических процессов вокруг этого поднятия и в западной части бассейна Вилькицкого отмечается в волновой картине на сейсмических разрезах в виде кальдерообразных элементов и вертикальных засвеченных зон, обусловленных мигрирующими потоками метана. Не исключено, что тектономагматическая активизация была связана со спрединговыми процессами в Евразийском бассейне.

Южнее в депоцентре субширотного сегмента Новосибирского (Благовещенского) бассейна обнаруживается довольно контрастная смена волновой картины в фундаменте. Это дает основание говорить о том, что к северу от этого депоцентра, по всей видимости, имеют распространение позднекаледонские комплексы элсмирид, которые, судя по всему, погружаются к югу под допозднемеловой (?) фундамент (Шипилов, 2016).

Представляется, что рассматриваемая континентальная окраина, а в геодинамическом отношении Новосибирско-Чукотская микроплита (с учетом дискуссионности вопроса о принадлежности Котельнического массива), ограничена с запада продолжением Южно-Анюйской шовной зоны, а на востоке - Чукотско-Канадской сдвиговой зоной (Шипилов, 2016; Шипилов, Лобковский, 2014). На западе плиты об этом свидетельствует согласованность ансамбля тектонических элементов, а на востоке - явный диссонанс между структурами севера чукотского шельфа и Арктической Аляски (рис. 2).

Работа выполнена при финансовой поддержке РФФИ в рамках научного проекта № 18-05-70012 «Развитие геодинамической модели эволюции литосферы Арктики в мезозое-кайнозое в связи с научным обоснованием заявки России в Комиссию ООН на установление внешней границы континентального шельфа РФ в Северном Ледовитом океане».

\section{Литература}

1. Богданов Н.А., Хаин В.Е., Розен О.М. и др. Объяснительная записка к Тектонической карте морей Карского и Лаптевых и севера Сибири м-ба 1:2 500 000. М.: Институт литосферы РАН. 1998. 127 с.

2. Верба М.Л. Палеозойские осадочные породы в осадочном чехле северной окраины Восточно-Сибирского моря и их вклад в общую оценку перспектив нефтегазоносности // Нефтегазовая геология. Теория и практика. 2016. Т. 11. № 4. 
3. Верниковский В.А., Добрецов Н.Л., Каминский В.Д., Лобковский Л.И, Шипилов Э.В. Геодинамика Центральной и Восточной Арктики // Материалы совместного заседания Совета РАН по координации деятельности региональных отделений и региональных научных центров РАН и Научного совета РАН по изучению Арктики и Антарктики. Екатеринбург, изд-во УрО РАН, 2010. С. 41-58.

4. Головачев Э.М., Шипилов Э.В. Линеаментные зоны моря Лаптевых // Известия ВУЗов. Геология и разведка. 1986. № 8. С. 106-108.

5. Лаверов Н.П., Лобковский Л.И., Кононов М.В., Добрецов Н.Л., Верниковский В.А., Соколов С.Д., Шипилов Э.В. Базовая модель тектонического развития Арктики как основа для подготовки обновленной заявки России в Комиссию ООН на установление внешней границы континентального шельфа // Арктика: экология и экономика. 2012. № 2 (6). С. 4-19.

6. Лобковский Л.И., Шипилов Э.В., Кононов М.В. Геодинамическая модель верхнемантийной конвекции и преобразования литосферы Арктики в мезозое и кайнозое // Физика Земли. 2013. № 6. С. 20-38.

7. Шипилов Э.В. О влиянии процессов молодого океанообразования на становление континентальных окраин Арктики // Седиментологические процессы и эволюция морских экосистем в условиях морского перигляциала. Книга 1. Апатиты: Изд-во КНЦ РАН. 2001. C.193-208. DOI: 10.13140/RG.2.2.29632.58885.

8. Шипилов Э.В. К тектоногеодинамической эволюции континентальных окраин Арктики в эпохи молодого океанообразования // Геотектоника. 2004. № 5. С. 26-52.

9. Шипилов Э.В. Базальтоидный магматизм и сдвиговая тектоника Арктической континентальной окраины Евразии в приложении к начальному этапу геодинамической эволюции Амеразийского бассейна // Геология и геофизика. 2016. № 12. С. 2115-2147.

10. Шипилов Э.В., Лобковский Л.И. Тектоно-геодинамические трансформации литосферы Амеразийского бассейна в кайнозое // ДАН. 2012. Т. 445. № 6. С. 663-669.

11. Шипилов Э.В., Лобковский Л.И. О субмеридиональной зоне сдвига в структуре континентальной окраины Чукотского моря и механизме раскрытия Канадского океанического бассейна // ДАН. 2014. Т. 455 . № 1. C. 67-71.

12. Шипилов Э.В., Шкарубо С.И. Тектоника и геодинамика областей молодого океанообразования // Тектоника и геодинамика: общие и региональные аспекты. Материалы Совещания. М.: ГЕОС. 1998. Т. 2. С. 281-284.

13. de Vera J. Structure of the Red Dog district, Western Brooks range, Alaska // A Thesis submitted in the fulfillment of the requirements of the University of London for the degree of Doctor of Philosophy Department of Geology Royal Holloway, University of London Egham, Surrey TW20 0EX, United Kingdom, December, 2005. 633 (664) p.

14. Elswick V.A, Toro J. Seismic interpretation and structural evaluation of the Hope Basin, Alaska // Geol. Soc. Am. 2003. V. 35. № 6. P. 28-42.

15. McDannell K.T.J. Toro J.K. Hourigan D. Harris. Thermochronologic constraints on Late Cretaceous to Cenozoic exhumation of the Bendeleben Mountains, Seward Peninsula, Alaska // Geochem. Geophys. Geosyst. 2014. V. 15. P. 4009-4023.

16. Shipilov E.V. Generations of spreading basins and stages of breakdown of Wegener's Pangea in the geodynamic evolution of the Arctic Ocean // Geotectonics. 2008. V. 42. № 2. P. 105-124.

17. Shipilov E.V. The Graben-Rift System of the Chukchi Sea // International Geology Review/ 1989. V. 31. P. $1097-1106$.

18. Tolson, R. B. Structure and stratigraphy of the Hope Basin, southern Chukchi Seas, Alaska // Geology and resource potential of the continental margin of western North America and adjacent ocean basins: Beaufort Sea to Baja California. Ed. by Scholl, D. W., Grantz, A., and Vedder, J. G. Houston, Texas, Circum-Pacific Council for Energy and Mineral Resources // Earth Science Series. 1987. № 6. P. 59-71. 